\title{
TUMOURS OF THE SALIVARY GLANDS, WITH THEIR AFTER-HISTORY.*
}

\author{
By R. KENYON, Liverpoos.
}

SALIVARY-GLAND tumours, though not of frequent occurrence, share with sebaceous cysts and ganglion a peculiar power to elicit in their possessors a morbid delight in their presence, with its attendant self-pity. This, with the luxury of an ever-sympathetic group of friends, makes them blind to the hideousness of their deformity and deaf to the warnings of the profession as to the ultimate outcome of this silent death. The knowledge of surgical failures, in patient and doctor alike, has weakened the demand for treatment and the object of this research was to investigate the after-history, causes of recurrence, and the pathological nature of salivary tumours, and to demonstrate that, in the majority of cases, surgery can cure.

'The material consisted of 124 cases of parotid tumours and 13 cases of submaxillary tumours, collected from the Thompson Yates Pathological Laboratory and the records of the Royal Infirmary.

The 124 cases of parotid tumour were classified as follows: Adenomata, 91 cases, including a case of lymphangioma and one of inflammatory origin ; Carcinomata, 27 cases ; Sarcomata, 6 cases.

\section{ADENOMATA.}

Out of the 91 cases of simple tumour, the after-history of 32 has been traced; of these, 29 were operated upon over five years ago. Of the 32 cases in which an afterhistory was obtained, 22 are alive and well; 1 died of an unknown cause; 1 died of angina pectoris without recurrence seven years after the operation; 5 have recurred; 3 under the five-year limit are also alive and well. In other words, 71.9 per cent have survived the five-year limit, while $\mathbf{1 5 \cdot 6}$ per cent have recurred. The average duration of known cure was well over eleven years.

Friology.-The age at the onset of discase (data available in 29 cases) averaged $30 \cdot 1$ years (youngest 16 years, oldest 54 ). Age at the time of operation (43 cases) 37 years (youngest a case of lymphangioma age 13, another age 15).

It is interesting to note that the persuasive influence for good of a doctor over his patient in these cases varies from 9 months to 20 years, and averages 7 years. Out of 78 cases, 59 occurred in women, 19 in men. No family history of similar tumours was obtained.

Trauma.-Out of 29 cases in which a record is available, 4 gave a previous history of blows on the cheek, ete. Mumps, scurlet fever with tonsillectomy, figure in individual cases.

PATnology.-Macroscopically the tumour is lobulated, partly solid and partly cystic, occurring on either side of the face without much distinction (left 21, right $2 \gamma$ ), bilateral in two cases, multiple in one. The heaviest recorded weight was $3 \mathrm{lb}$. $10 \mathrm{oz}$, removed by Mr. Rushton Parker; but at that time malignant change had probably taken place, and early and repeated recurrence followed (Fig. 67). Keen reported a case in which the tumour weighed $7 \mathrm{lb}$.

Much has been written on the origin of these tumours, and their terminology has changed with the prevailing pathological whim: they have becn styled mixed tumours,

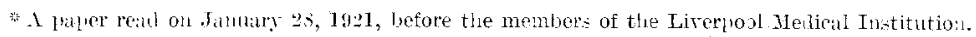




\section{TUMOURS OF THE SALIVARY GLANDS}

endotheliomata, embryomata, teratoblastomata. The anount of indefinite evidence for these names contrasts vividly with the decided opinion I obtained from Mr. Paul and Mr. Thelwall Thomas that primarily the lesion is an adenoma. Examination of over seventy sections leads me to agree with them, and I recognize two types: the diffuse and the acinar.

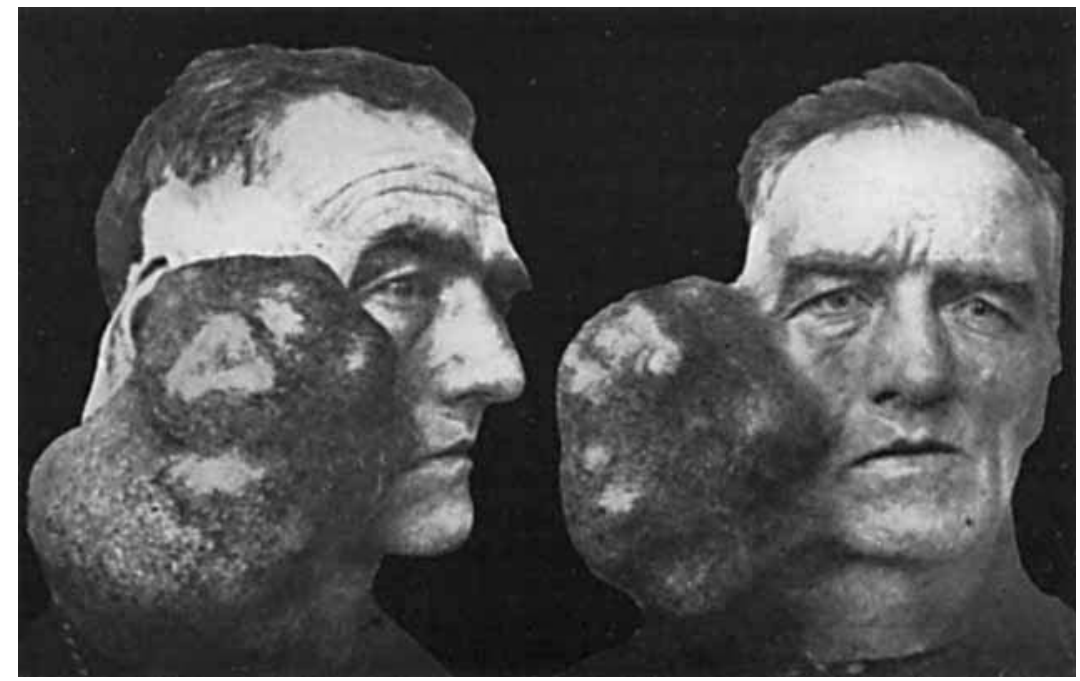

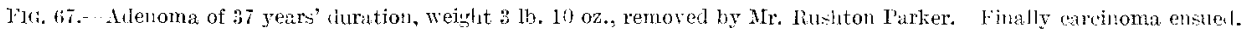

The diffuse type is illustrated in the case of Miss J, M. (Fig. 68), who noticed a swelling on the left side of the face at the age of 51. Two years later, Nov. 1909, it was removed by Mr. R. A. Bickersteth. In July, 1920, she was alive and well [2313]. It is also illustrated by Fig. 69, a recent case; this tumour was removed by Mr. R. F. Kelly.

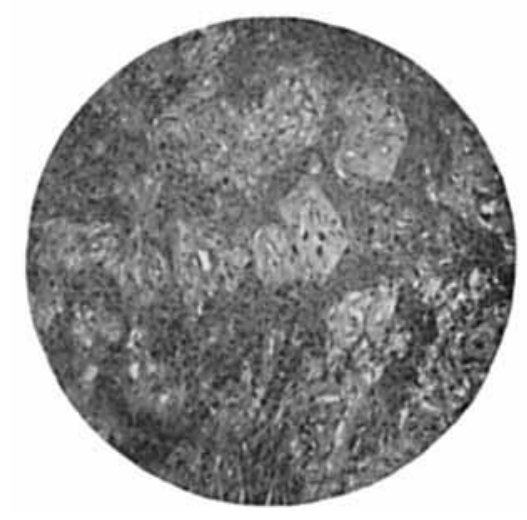

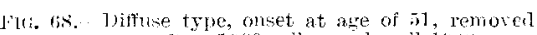
two year after, 1909 , alive and wall $14: 0$.

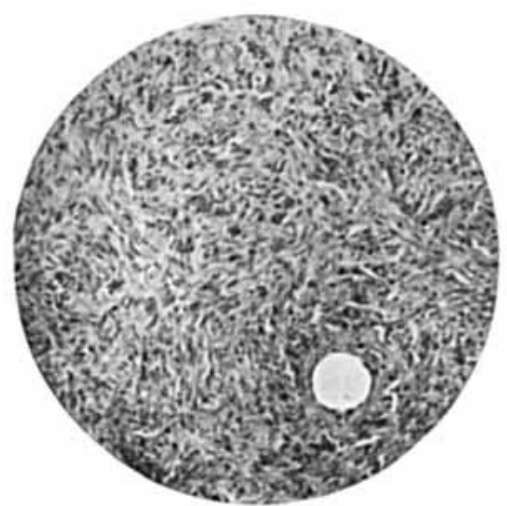

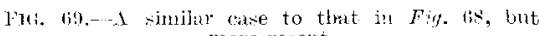
more recent.

The acinar type is shown in Fig. 70-Miss D. B., age 19, a recent case of typical 'mixed tumour', removed by Mr. Litler Jones. For a time I was disposed to think the latter were of duct origin, while the former arose from gland proper; but closer study showed that both diffuse and acinar formations oceur in the same tumour. Frazer ${ }^{1}$ believes these tumours are duct adenomata. The course of events seems to be an adenoma, 
mucinous degeneration with epithelial or degenerative cyst formation, inspissation or liquefaction, necrosis, and, later, formation of cartilage. In innocent growths I did not find any outer layer of basal cells, though such is present in many cases of cancer. The anatomical view that the cartilage is derived from branchial clefts has little evidence to support it. Purely bone or cartilaginous tumours do not occur in this series, and sarcomata form only 5 per cent of the malignant cases.

The endotheliomatous origin of these tumours $I$ have not dealt with, but endothelium can often be seen in the smaller blood-vessels and the capillaries presenting no atypical appearance. To support this theory of origin it is necessary to imagine a flat scale-like cell, under an unknown stimulus, changing into a sphere or cube, and, though derived from mesoblast, capable of producing carcinoma in the majority of cases when malignancy ensues : and one must imagine also a differential stimulus capable of exciting to overgrowth the ill-defined and little-known perivascular endothelium, yet leaving intact that of the normal blood-vessels and capillaries.

Fig. 71 shows an adenoma with well-defined acini, distended with mucus, removed from Miss N., age 50 at time of operation, by Mr. Thomas in December, 1912. Reported "quite successful", November, 1920 [1991].

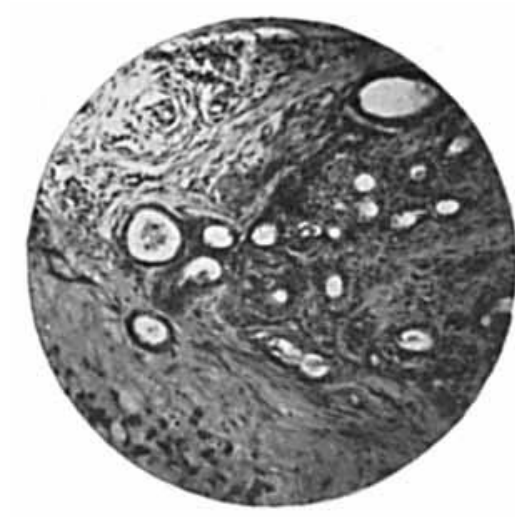

Fisi. To.- Leinar trje of mrotid adenoma, at ate of 1i. liccent case.

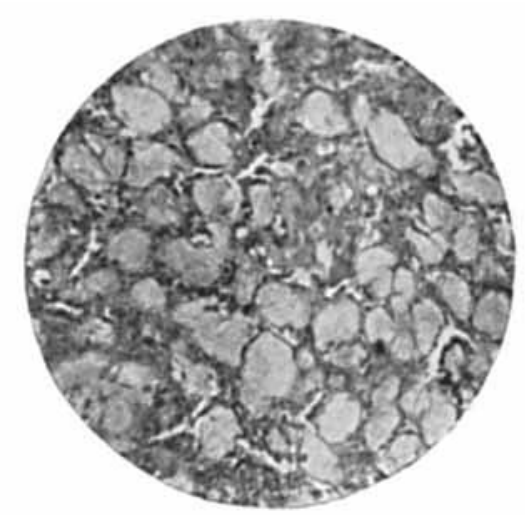

F[a. i 1,--A similar case to Fig. 70; acini distended witls mucis

Fig. $i 2$ shows the second stage of the diffuse mass, mucinous degeneration, from D. J., male, age 41 , in $190 \%$. The tumour appeared in 1901 on the right side of the face. It was removed nine months later and diagnosed cancer. It recurred, and was again removed in 1904, with immediate recurrence. Yet simple enucleation in 1907 by Mr. Bickersteth was so successful that in June, 1920, the patient wrote : "I regard myself as being completely cured " - a fact discrediting the idea that operative interference favours recurrence and shortens the life of the patient.

Sruptoms AND Signs.-A painless, slowly-growing swelling at the angle of the jaw. If pain is present, then, microscopically, a superadded inflammation is present. The slow growth is very characteristic, but 7 cases complained of recent sudden increase which evidently caused alarm. In these cases no malignant change had occurred; possibly the capsule had been so thinned as to yield, and liberate the cells from their constrained position beneath-a point I shall refer to in dealing with the pathology of recurrence. The lobule of the ear is early displaced outwards, but meatal obstruction is rare-one case in our scries, which was relieved by syringing. Later, redness and ulceration of the skin occur. The lymphatic glands are not enlarged except from other diseases. Facial paralysis is unrecorded except as a post-operative event or with the onset of carcinoma.

Treatment.-The situation of these tumours renders opcration in any great enlargement a formidable proceeding, and the records show evidences of great difliculties from 


\section{TUMOURS OF THE SALIVARY GLANDS}

the operator's point of view-ligation of the external or internal carotid arteries, or both, with the internal jugular vein or the common carotid artery, had to be performed so frequently in the middle of the operation that ligation of the external carotid should be a useful preliminary in all cases of great enlargement.

The type of incision must vary with the size and position of the tumour. One patient complained of the incision which swings round the jaw half an inch from it-she was evidently troubled with the anxsthesia and hyperæthesia due to division of the branches of the great auricular nerve. An incision described by Ochsner ${ }^{2}$ would avoid this complication; the incision commences midway between the lobule of the ear and the angle of the mouth, and swings downwards and gradually backwards to about half an inch below the angle of the jaw.

Seven post-operative cases of facial paralysis occurred, of which 6 have been traced, and with one exception no mention is made of this disfigurement; so that I am forced to believe that the tension relaxation of this nerve by removal of the tumour produces more cases of facial paralysis than the surgeon's knife. No cases of salivary fistula have occurred. Treatment with spirit biniodide, scraping of imperfectly-removed tissue, to express or kill any liberated cells, do not seem to influence recurrence, but are safeguards of great comfort to the operator.

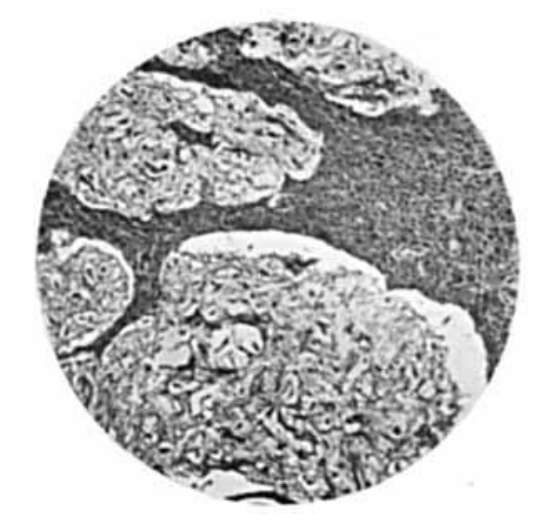

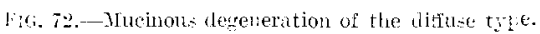

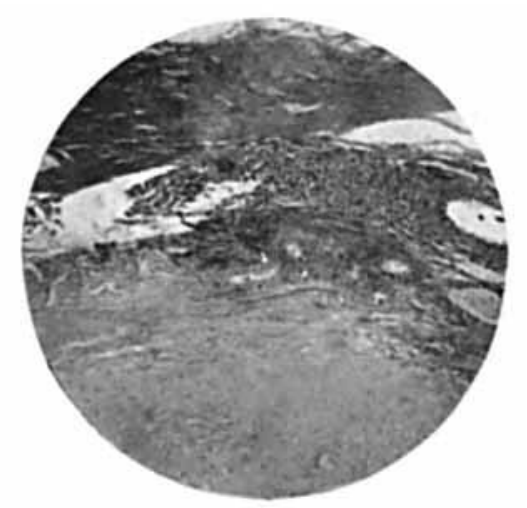

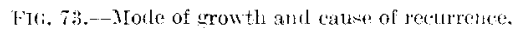

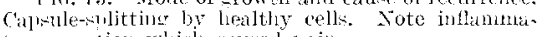
tory reaction which aused pain.

Recurrence.-Apart from the incomplete removal of very large adenomata and the development of malignaney in a simple tumour (see later), recurrence took place in 9 out of 32 cases traced, i.e., $28 \cdot 1$ per cent. Three patients still possess their tumour and hesitate to undergo further operative treatment; 2 are being controlled by radium ; 3 recurrent cases (one the lymphangioma) are cured if the five-year limit be accepted; another is alive and well, but within this limit. Immediate recurrence occurred in 5 out of 9 cases in which accurate history is available. Re-operation time averages five years in 11 other cases.

An examination of the sections of 70 cases of adenoma shows that the epithelial cells persist longest either in the extreme centre of the degenerate mass, probably around a blood-vessel ; or, what is more important from the surgical point of view, immediately bencath the cver-thinning capsule. Fven in the most degenerate tumour, small elongated groups of cells will be detected splitting the layers of the capsule and leading a more healthy existence than in the rest of the tumour.

If the surgeon enucleate the adenoma rather than excise it, he may inadvertently split the capsule, liberate the soft epithelial cells contained between its layers, and run the risk of recurrence unless treatment with cautery or strong antiseptic be employed. 'This process of capsule-splitting seems to be the method of growth during life, and in Fig. 73 
we see both recent splitting and resulting inflammatory reaction in the effort to stem the progress of tumour formation. Judd also refers to this in the Mayo Clinics, 1910. The figure is from E. M., female, age 48 at time of onset. Two years jater a painful tumour, fixed by inflammation, was enucleated, in 1913. By 1920 no recurrence had taken place, and there was 'no disfigurement', for which she is duly grateful to Mr. Bickersteth.

\section{AFTER-HISTORIES OF 32 CASES OF ADENOMA.}

Case 1.-Mrs. A. P., age 31. History of mumps [7901]. Tumour noticed, 1911. 'Typical mixed tumour" removed 1913. Recurrence, removed, 1916. Immediate recurrence, and incomplete operation, August, 1917. "Ordinary type of parotid tumour, apparently not malignant," Oct. 27, 1920. Husband writes operation a complete failure : she is "under treatment of some sort at Carnarvon to lift the tumour and not the roots". Life history of tumour to date, nine years-il surgical failure.

Cuse 2.-Miss S. J. R. [3357]. Tumour appeared at side at the age of $2 \%$, and was excised at Wrexham. Recurred seven years later. Mr. Thomas removed it live years later, Nov. 22, 1917. Reported "quite successful" on May $23,1920$.

Case 3.-Mrs. A. N. [2699]. Age 35, when tumour appeared on right side in 1899 . Remover after recent rapid growth, 1915. Report, May 25, 1920 , " Very grateful to Mr. Thomas not only for the operation, but for saving my lace from being drawn ".

Case 4.-Mr. R, J., at the age of 24, noticed tumour with aching pain. Removed, July 29, 1910. Quite a success for a number of years- now as large as ever (due in some mystical way to army life).

Case 5.-Miss N. [1901]. Age 50 at time of operation by Mr. Thomas, December, 1912. Nov. 5, 1920: Quite successful. Mucous adenoma (see Fig. 71).

Case 6.-Gilen Mc'T. After 10 years' delay, tumour was removed by Mr. Paul in lebruary, 1906. Dec. 2, 1920: Alive and well.

Case 7.-Kitty C. Noticed tumour at age of 21. Nine years later it was enucleated, Feb. 19, 1907. Feb. 10, 1920:A complete success, thanks to Mr. Paul.

Case 8. - Miss W. [1178]. Age 38 at time of operation by Mr. 'Thomas on April 30, 1910. Left side. July 5, 1920 : Dr. O. Evans reports alive and well.

Casc 9.-Miss O. B. [1105]. Age 30 at time of onset. Operation two years later by Mr. Thomas, left side, Feb. 2, 1910. Tumour an inspissated ccll-less mass of degenerated tissue. Dr. O. T. Evans reports her alive and well on July $5,1920$.

Case 10.-Rev. G. [648]. Age 50 at time of operation. Enucleated by Mr. Thomas, April 18, 1909. Died in 1915 of angina pcetoris. No recurrence. 1)r. Arkle.

Case 11.-Mr. J. H. [6753]. Age 64 at time of operation by Mr. Kelly, September, 1915. Com. plete suecess, and thanks the operator on Nov. $4,1920$.

Case 12.-Miss M. T. [27\%6]. At the age of 25, tumour appcared on right side. Came suddenly and was painful. "Remembers straining jaw". Removed three years later by Mr. Thomas in 1915. Writes on May $2 \%, 1920$, result " quitc satisfactory".

Case 13.-Mr. E. J. Age 23 when operated upon, Nov. 23, 1904, by Mr. Paul, whose pathological diagnosis was adenoma. No trouble since. Dec. 18, 1920: Very grateful to Mr. Paul and infirmary staff. Note: 16 years without recurrence.

Case 14.-Mrs. A. [998]. - First operated upon in 1903 at the age of 56 . Had at recurrence and was again operated upon in October, 1909, by Mr. Thomas. Dr. Marsden writes, " Now 7.4 years of age and in the best of health". A pathologist reported cancer in 1909.

Case 15.-Mr. J. E. J. Recurrent tumour removed by Mr. Rushton Parker, Jan. 31, 1907. Nov. 10, 1920: "Successful in every way" for 13 years.

Case 16.-Mrs. M. K. Developed a tumour at age of 31. Removed by Mr. Bickersteth five years later, March 22, 1909. In May, 1920, alive and well.

Case 17.-Mrs. H. [587]. Operated upon by Mr. Thomas on Feb. 11, 1008. Dr. Nixon reports alive and well on June 29, 1920, and adds a useful research note that this had bcen the only case in his practice.

Case 18.-Miss Jessic T. [3057]. Age 21 at time of operation by Mr. Thomas in December, 1916. I.eft side. May 14,1920 : Is very glad she had it removed. No recurrence. 


\section{TUMOURS OF THE SALIVARY GLANDS}

Case 19.-MIrs. J. M. [2313]. Tumour appeared at age of 51. I.eft sirle. Two vears later, on Oct. 1, 1909, it was removed by IIr. Bickersteth. Reprort on .July 18, 1920, says, "Quite all right since the operation".

Case 20.-Mrs. E. M. [4765]. Age 48 at onset; two years later tumour removed by Mr. Bickersteth, in 1913 (Fig. 73).

Case 21.-Mr. D. J. [5594]. Fig. 72 (see text, p. 78).

Case 22.-W. E. [14\%6]. Agc 2.5 when tumour appeared in 1905. Removed by Mr. Thomas in 1911. Dr. Arthur Walker reports alive and well, .July 8, 1020.

Case 23.--.M. M. [2951]. Iultiple recurrence--tumour still present. In 1911 this patient, at the age of 52, developed a tumour which was removed the same year at West Hartlepool. In 1912 it had recurred and was removed at the Royal Infirmary. In 1914 it recurred again and was removed. In 1919 a rerurrence was treated with radium by Dr. Holland. Total duration of the disease is eleven years to date.

Case 24.-Miss A. L. Now married, with children. At the age of 27 had an adenoma removed. It recurred in 1909 and rancer was suspected, but there is no histological evidence of this. 1)r. Carse reports that recently it has again recurred, and he is hoping to obtain further surgical treatment.

Case 25.-.J. G. [5859]. Trauma fifteen months previonsly. Tumour removed, April 2\%, 1914. Recurred, February, 1916. Removed, January, 1917. Recurred ; radium prescribed, and said to be cured. Recurred, April, 1919. Attends monthly for radium and has improved sulficiently to seck a higher post; she speaks in generous terms of the treatment.

Case 26,-W. H. Appeared at age of 30 -operated upon by Mr. Kelly five years later. Yiddle of 1920 , alive and well.

Case 27.--J. J. [162]. Tumour appeared at age of 31. In .Tanuary, 1905, tunour was enucleated by Mr. Paul. Fifteen years later, Bec. 10, 1920, was alive and well.

Case 28.--Miss McC. Age 30 at time of operation in 1915. Died 1 year later, cause unknown.

Case 29.- Miss M. B., age 43 at time of operation, Jan. 1, 1917. Alive and well, Nov. 8, 1920.

Case 30.-Miss M. P. T. At age of 20 noticed swelling on right side of face. Enucleated Dec. 3, 1917-eight years later. Alive and well, May, 1920.

Case 31.-Miss M. B., age 13. Operated upon for 'cystic lymphangioma' in 1892. Recurred, and was removed in 1895, and again in 1897. Since then alive and well, 1920. Mr. Rushton Parker.

Case 32.-Miss P. W. [1710]. Age 40 at time of operation by Mr. Thomas, A chronic inflammatory thickening of parotid gland. Excised and curce.

Case 33 (too late for inclusion).-Mr. E. E. Age at onset 71. Operation three years later. Died one year afterwards from 'cystitis'. No recurrence.

Case 34 (too late for inclusion).-Mr. G. E. Age at time of operation 2.5; tumour removed by Mr. Rushton Parker, 1892. Alive and well, March, 1921.

\section{CARCINOMA.}

Of the total 124 cases, $27(21.8$ per cent) were carcinomatous on section. Of these, 5 cases were traced and 2 others are known to have inoperable recurrences. The histological appearances, supported in 4 cases by the elinical history, suggest that carcinoma. was engrafted on a simple tumour in 7 out of 20 cases ( 35 per cent).

Age.--Excluding cases arising as simple adenomata, the average age is $\mathbf{4 6} \cdot 4$, sixteen years later than the adenoma. The malignant change in adenomata appears to occur about the $381 \mathrm{~h}$ year. The average operation age is $48 \cdot 1$ years. The delay of $1 \frac{1}{2}$ years ( 5 cases) is less than in simple tumours, but still significant.

Sex.-Again the preponderance of females to males is noticeable-12 to 8 .

Trauma occurred in 2 out of 12 histories. One patient played a wind instrument.

Pathology.-Two types can be recognized: (1) Spheroidal-celled cancer ; (2) Adenocarcinoma, in which the cells are more cubical. Of the primary cases, examination of the sections shows 9 spheroidal-celled cancer (Fig. 74) and adenocarcinoma (cubical-celled) (Fig. 75). Those deemed to arise in simple adenomata show 4 spheroidal-celled cancer and 3 adenocarcinoma (cubical-celled).

VOL. IX. - NO. 33. 
Fig. 74,-Mrs. J. R. Patient of Mr. Thomas. Onset at age 49, with pain. Twelve months later the size of a Tangerine orange. Growth encapsuled-removed August, 1917. Recurred in glands. Removed, March, 1918. Again recurred in August, 1918, and glands showed spheroidalcelled cancer. Later history unknown; but no reply to so recent a case is significant.

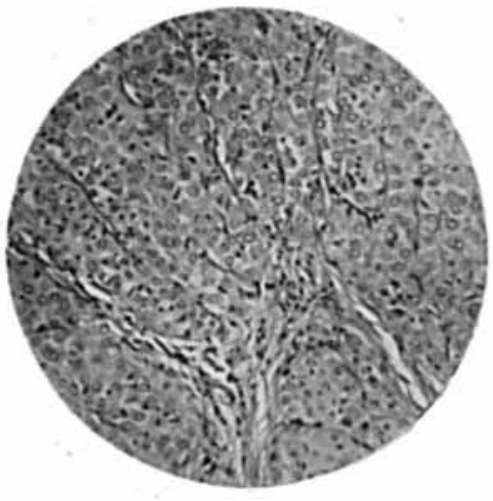

FIG. 74.-Spheroilal-celled carcinoma.

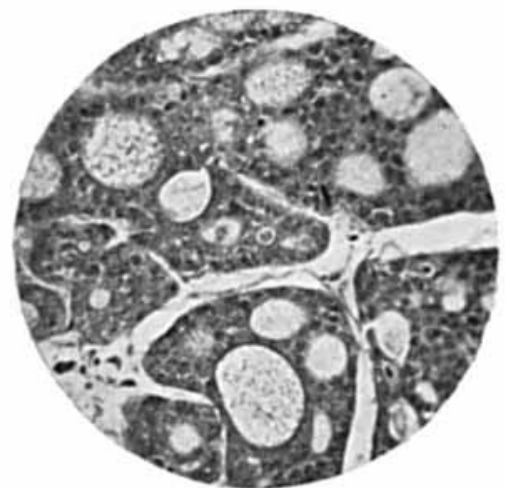

FIG. 75.-Cubical-celled adenoearcinoma.

Fig. 75.-Miss L. B. Age 32 at onset in 1911. Tumour on left side of face adherent to external jugular vein ; within one year had caused facial paralysis. Removed by Mr. Thomas in January, 1912. A cubical-celled carcinoma with marked inflammatory reaction. Dr. Pethick writes that growth recurred locally and orbit became involved. Patient died in August, 1917. Radium failed to relieve.

The histological features are the well-defined basal layer, the healthy and highlyorganized stroma, the small amount of degeneration (Fig. 76 : Miss V., age 20 ; Mr. Paul's case ; history unknown), and the more marked inflammatory reaction of the tissues, with direct infiltration of parotid tissue.

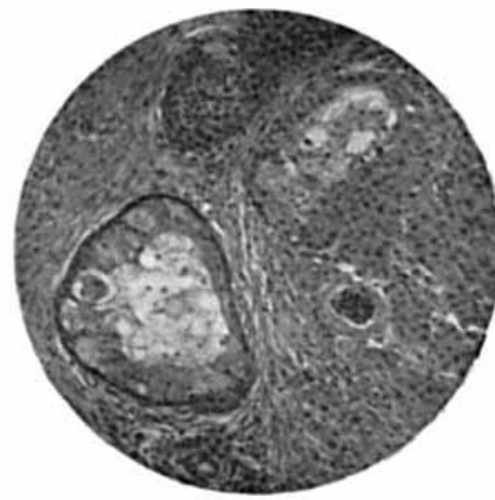

FIG. 76.-Spheroidal-ielled careinoma with small aress of mucous degeneration.

\section{SyMPTOMS AND SIgNS.-}

1. Rapid growth.

2. Pain at onset or within a few months, in eye or ear in 7 out of 11 cases.

3. Facial paralysis. Four out of 11 cases prior to operation, 3 cases after operation, one of the latter known to have been permanent.

4. Early fixation of tumour; interference with jaw movements; occlusion of external auditory meatus ; invasion of the orbit, with subsequent blindness; occlusion of pharynx, depression of palate; ulceration of skin and secondary hæmorrhage in all cases recorded in this small group. Involvement of lymphatic glands is late in occurrence, and ofien the site of post-operative recurrence.

Results of Treatment.-

Mr. McB.-Died 1 year after last operation. Primarily simple; duration 12 years. (See Fig. 78).

Mr. C.-Died 4 years after last operation. Primarily simple; duration 17 years.

Mr. K.-Probably died. Inoperable four vears after last operation. Primarily simple; duration 45 years.

Miss F L.-Primarily simple; 3 years' duration. Now 15 months since complete excision by Mr. Litler Jones. Alive and well; no local recurrence; but similar tumour on opposite side has progressed-this was present at time of opcration. 


\section{TUMOURS OF THE SALIVARY GLANDS}

Irs. E. F.-Died 5 years after operation. Primarily simple; duration 10 years.

Mr. C. S.--Inoperable, 2 years after operation. Recurrence. Previous operation 6 years ago. Miss I. B.-Died 3 years after an operation ; total duration $4 \frac{1}{2}$ years.

Mr. J. C.-Died 2 years atter an operation; duration 4 years.

The average duration of primary cases seems to be about 4 years.

\section{Case: Records.}

Mrs. E. F.-Age 35 at onset of growth ; constant pain in right ear. Five years later Mr. Litler Jones had the unenviable task of an incomplete removal in November, 1912-already the glands were involved. The patient died, writes Dr. Williams, in 1917. (Fig. 77.)

Mr. P. McB.-A case of carcinomatous change in a simple tumour. Onset at age of $\mathbf{5 4}$. Twelve years later, 1910, recent pain brought patient to the surgeon. The tumour was then 6 in. in diameter, and facial paralysis was present. The common carotid and external and internal jugular veins had to be tied and the sternomastoid divided. (Fig. 78).
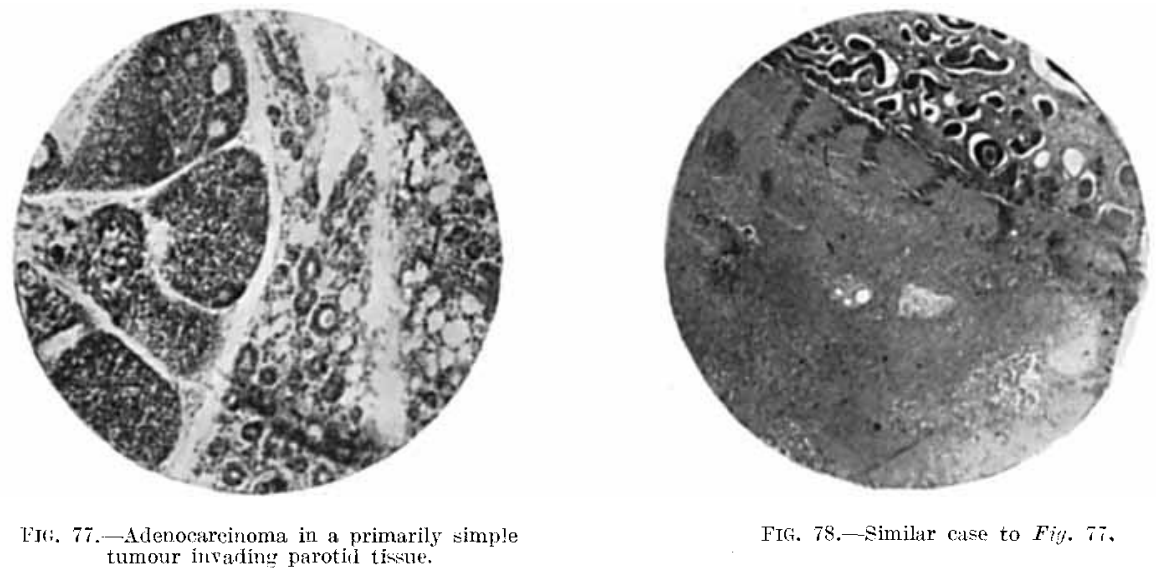

FIG. 78.--Similar case to $F i \gamma, 7 i$,

Mr. W. C.- Onset prior to 1891, when patient was operated upon at age of 37.4 recurrence took place, and 12 years later a second operation, followed a year later by a third. His son writes that patient passed away in great pain, and the throat had become closed entirely, in 1907.

Mr. W. K.-Onset at the age of 16. Tumour weighing $3 \mathrm{lb} .10 \mathrm{oz}$-the largest of the series-removed by Mr. Parker 37 years later, in 1900 . In 1905 recurrence and removal, again in 1906, declared inoperable in 1908. No reply to inquiries, 1920. Section shows a simple adenoma becoming malignant in 1900 .

Miss F. L. [9935].-Age 49 at onset of growth: inflamed for 4 months (painful). Bilateral. Total excision of the tumour on the left side 3 years later, in 1919 ; that on the right has continued to grow. Left facial paralysis is present (post-operative) Jan. 16, 1921. Section shows large cystadenomata; cartilage and areas of subcapsular round-celled inflammation; but an assoriated gland showed columnar-celled carcinoma. Total excision by Mr. Litler Jones; so far successful, 15 months after operation.

Mr. C. S.-Age 4; at first operation, 1912. Recurred and removed 4 years later. Recurred and inoperable, August, 1918. No reply from M.O.

Mr. J. C.-Age 61 at onset of swelling in right parotid region : rapid growth, with local pain. Two years later an unsatisfactory removal by Mr. Kelly in January, 1914, Died February, 1916, from the disease. Columnar-celled cancer.

\section{SARCOMATA.}

Six cases in 124: 3 females, 2 males, 1 doubtful. Of these, one case only was traced. Ages of patients : $20,44,70,55$.

Patiology.--The usual round- or spindle-celled varieties.

Clinical Features. - Sudden pain, facial paralysis, discharge from the ear, difficulty in opening the mouth, pharyngeal obstruction, are recorded.

Radium was used in one case; end-result unknown; patient could not be traced. 


\section{4}

\section{THE BRITISH JOURNAL OF SURGERY}

A sarcoma, spindle-celled, with alveolar formation, occurred in a patient, J. D., a woman, age 5.5. After three years it was the size of a walnut, had produced facial paralysis, and involved glands. Total excision with an area of skin by Mr. Thomas in January, 1917, failed;

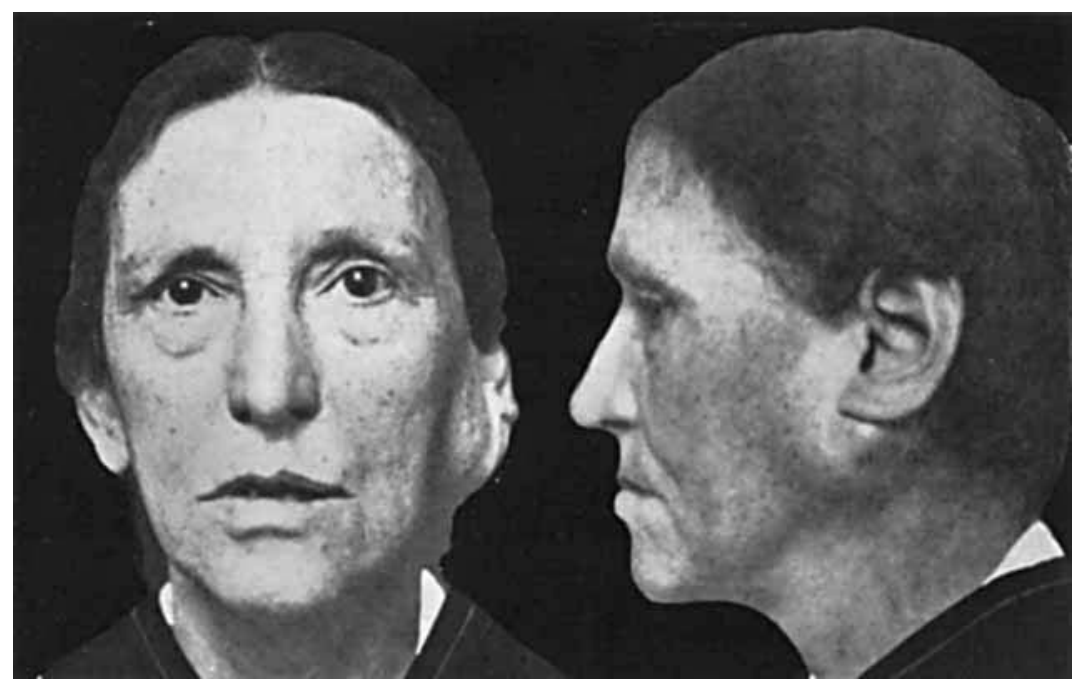

Jic. 79--Alveolar sarcoma; facial maralysis ind involver glands.

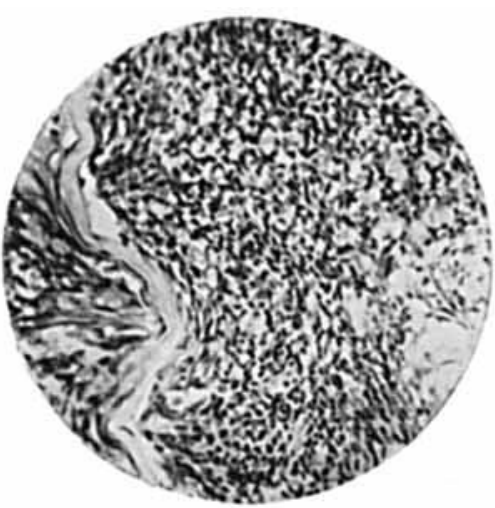

Fig. 80.- Same case as Fiy. 79.

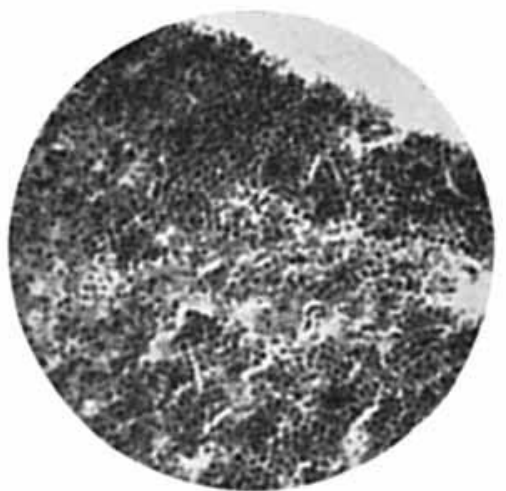

IT(*. 81.-.-Round-celled sarcoma of parotid gland.

the tumour recurred 18 months later. 1)r. Porterficld kindly reported that the patient died in 1919. (Figs. 79, 80.)

A round-celled sarcoma occurred in a girl, age 20, and was removed by Mr. Jeans in August last. (Fig. 81.)

\section{SUBMAXILLARY TUMOURS.}

The 13 cases collected did not offer much for investigation; in only one case was the after-history obtained. On analysis, 8 cases were adenomata, 4 carcinomata (3 spheroidal-celled, 1 cubical-celled), 1 sarcoma. Sex distribution was equal in the simple cases. The average operation age was $3 \tilde{5} \cdot 6$ years. One tumour had existed 15 years.

Figs. 82, 83.-Mr. R. H.-- Died at the age of 50, 5 months after an operation for carcinoma of the submaxillary gland; the lymphatic glands were involved at time of operation. At death secondary deposits were present in the lungs. Patient of Dr. J. C. Matthews. 


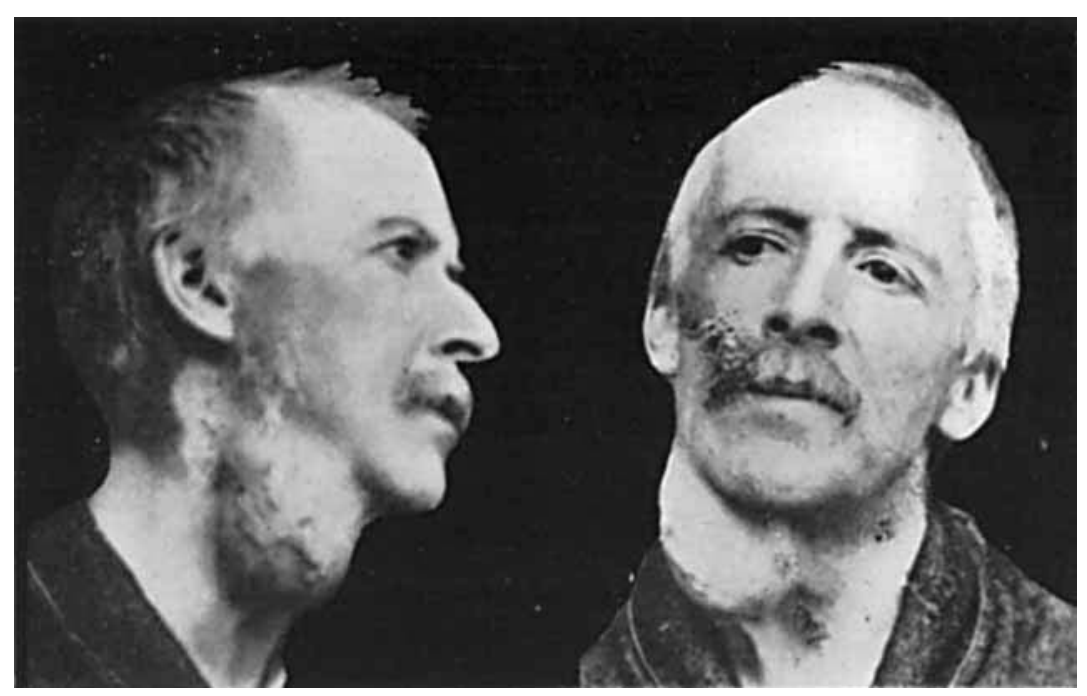

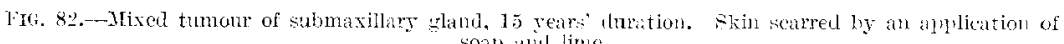
soap and lime.

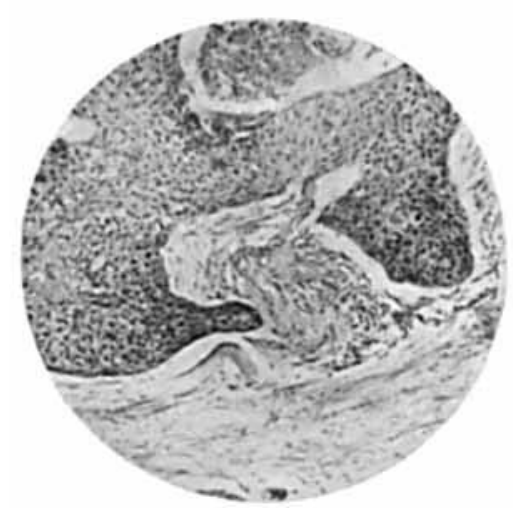

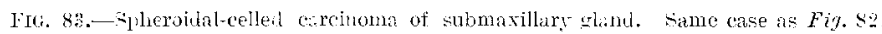

\section{SUMMARY AND CONCLUSIONS.}

1. Of cases operated upon for salivary-gland tumours, 137 have been inrestigated, and the after-histories of 40 obtained, the majority of which are at least 5 years after the operation.

2. Of these, 124 cases occurred in the parotid and 13 in the submaxillary gland ; of the former, the proportion of females to males was $59: 19$ in simple cases, $12: 8$ in carcinoma, $3: 2$ in sarcoma, and about equal in those of submaxillary origin.

3. Of the 124 parotid tumours, $91(73 \cdot 4$ per cent) were adenomata (this tumour is also called embryoma, endothelioma, and mixed tumour), 27 (21.8 per cent) were cancer, and $6(4.8$ per cent) were sarcoma. Of the cancer cases, 7 out of 20 (35 per cent) arose from degeneration of an adenoma.

4. Two varieties of adenomata were recognized, the diffuse and the acinar; and two varietics of carcinoma, the spheroidal-celled and the cubical-celled (adenocarcinoma). 
5. Of the adenomata operated upon over 5 years ago, 15.5 per cent have recurred. Recurrence was immediate in the majority of cases, or under 12 months. It is due to the liberation of healthy cells so frequently seen splitting the capsule in the sections examined. Capsule-splitting with the resultant inflammatory reaction explains the sudden increase in size and pain so often described in the history of the patient.

7. Excision rather than enucleation would diminish the risk of recurrence due to leaving remnants of capsule; and preliminary ligation of the external carotid artery is advisable in any large adenoma or malignant growth.

8. Facial paralysis was not met with prior to operation in the simple cases. Postoperative facial paralysis is more frequently due to tension relaxation of the nerve by removal of the tumour than to nerve section, and is therefore usually temporary.

9. The contention that operation hastens inoperable recurrence, shortens life, or causes disfigurement has no support in this research; and the fact that 35 per cent of cases of carcinoma arise in simple tumours of long standing should serve as a warning to those willing to allow a pre-operative delay of 7 years in primary cases and $\mathbf{5 . 5}$ years in recurrent cases.

I wish to thank Professor Ernest Glynn for suggesting this subject for investigation, and for helpful criticisms; Mr. Rushton Parker, Mr. F. T. Paul, and Mr. Thelwall Thomas for material which they willingly placed at my disposal; and those general practitioners who have responded to the call for information without which this paper could not have been written.

\section{REFERENCES.}

"Frasisr, A., "Mixed Tumours of the Salivary Gland", Surg. Gynecol. and Obst., xxvii, No. 1. 2 Ochsner, A. J., Surg. Clin. of Chicago, 1919, Aug. 